\title{
PERFIL GEOGRÁFICO (GEOGRAPHIC PROFILING): METODOLOGIA E ESTUDO DE CASO DE CRIMINOSOS EM SÉRIE ATUANTES EM BELO HORIZONTE
}

\author{
Antônio Hot Pereira de Faria \\ Polícia Militar de Minas Gerais \\ Centro de Pesquisa e Pós-Graduação, Belo Horizonte, MG, Brasil \\ hot.pmmg@gmail.com
}

\begin{abstract}
RESUMO
Este artigo discute a metodologia denominada Geographic Profiling, voltada para a análise preditiva de bases operacionais de criminosos seriais. O objetivo é apresentar e aplicar a técnica de Geographic Profiling ao estudo de eventos criminais desencadeados por criminosos em série que operaram em Belo Horizonte, entre 2011 e 2013. Foi realizada abordagem teórica do comportamento espacial criminal e um estudo do perfil geográfico de criminosos seriais que operam em Belo Horizonte. Os resultados indicam que o nível de assertividade da técnica foi verificado e comparado com os endereços residenciais conhecidos dos infratores, assumindo que o local de residência é uma provável base de operações. Os resultados do software RIGEL obtiveram uma taxa de acerto esperada média de $6,94 \%$, o que representa um índice satisfatório de precisão quando comparado com outros trabalhos. Dos 106 perfis geográficos, 90 (85\% dos casos) possuem pelo menos um endereço válido conhecido dentro da área de busca criada pela RIGEL. Este estudo contribui para preencher uma lacuna na literatura brasileira quanto à falta de construtos teóricos e análises empíricas sobre o Perfil Geográfico no âmbito da Geografia do Crime. Além disso, este estudo oferece uma rotina metodológica e resultados empíricos, que podem subsidiar investigações criminais, funcionando como referência para comparações em trabalhos futuros.
\end{abstract}

Palavras-chave: Geografia do Crime. Comportamento Espacial. Análise Espacial.

\section{GEOGRAPHIC PROFILING: METHODOLOGY AND CASE STUDY OF SERIAL CRIMINALS OPERATING IN BELO HORIZONTE}

\begin{abstract}
This article discusses the methodology called Geographic Profile, concerned with the predictive analysis of operational bases of serial criminals. The main objective of this work is to present and apply the Geographic Profiling technique to the study of criminal events triggered by 114 serial criminals operating in Belo Horizonte, between 2011 and 2013. To do so, a theoretical framework is developed, conjugating behavioral spatial approaches of criminal phenomena, still unexplored in Brazil, and a study of the geographic profile of serial criminals operating in Belo Horizonte. Results indicate that the level of assertiveness of the technique was verified and compared with the known residential addresses of violators, assuming that the place of residence is a likely base of operations. RIGEL software outputs obtained an average expected hit rate of $6.94 \%$, which represents a satisfactory index of accuracy when compared with other published works. Out of the 106 geographical profiles generated by RIGEL, 90 ( $85 \%$ of the cases) have at least one valid address known within the search area created by RIGEL. This study contributes by filling a gap in the literature regarding the lack of theoretical constructs and empirical analyses on Geographic Profile within the scope of Crime Geography, most notably in Portuguese language. Besides this study offers a methodological routine and empirical results, which can subsidize criminal investigations, working as a benchmark for comparisons in future works.
\end{abstract}

Keywords: Crime Geography. Spatial Behavior. Spatial Analysis.

\section{INTRODUÇÃO}

O estudo do fenômeno do crime por meio do enfoque geográfico é uma alternativa para se entender os contextos e as dinâmicas sociais e comportamentais, envolvidos na prática de delitos, e que se expressam no espaço. 
Trabalhos têm comprovado a existência de padrões espaciais no cometimento de crimes. Crimes, ofensores e vítimas, seguem padrões espaço-temporais de suas distribuições e áreas de ação (BRANTINGHAM; BRANTINGHAM, 1981, 1984; BURSIK, 1988).

O Perfil Geográfico (Geographic Profiling ou geoprofile) é uma técnica de análise espacial que avalia as localizações conhecidas de eventos criminais, os quais são conectados geograficamente a uma base operacional desconhecida, a fim de determinar sua localização provável. A base de operações pode ser a casa do infrator, seu local de trabalho, a casa de um amigo ou algum outro local frequentado pelo ofensor.

Logo, sabendo-se de uma série de crimes perpetrados por um mesmo indivíduo pode-se realizar uma análise preditiva dos locais mais prováveis de se encontrar esse criminoso.

O objetivo desta pesquisa é apresentar a técnica Geographic Profiling, dentre as possíveis abordagens comportamentais para entendimento do crime como fenômeno espacial, além de realizar estudo empírico de eventos praticados por criminosos em série em Belo Horizonte no período de 2011 a 2013.

O estudo justifica-se pela predominância de trabalhos sobre o crime realizados a partir de pacote de eventos perpetrados por diversos autores num determinado recorte espaço-temporal (perspectiva transversal), em que pese o crime ser cometido por um indivíduo. Assim, o trabalho propõe-se a realizar um estudo longitudinal, que explora os eventos desencadeados por indivíduos numa série de fatos ao longo do tempo, e o conhecimento do comportamento criminal de autores reiterados de crimes tem potencial de contribuir para a redução das taxas de criminalidade. Neste sentido, Kahn (2014) a partir da literatura norte-americana, afirma que a prisão indiscriminada de criminosos pouco ativos é um desperdício, mas prisões focadas em criminosos reincidentes e produtivos podem contribuir para a redução do crime.

Do ponto de vista prático, a partir do trabalho pretende-se conhecer o comportamento criminal no espaço, em especial de autores contumazes de delitos, de forma que os resultados contribuam com a inteligência policial, focada na prevenção e repressão qualificada de delitos.

Alia-se o fato de que teorias, métodos e técnicas empregados nesse trabalho não foram utilizados anteriormente em estudos nacionais sobre o crime, introduzindo uma perspectiva que tem potencial para se consolidar e contribuir para a investigação policial e prevenção criminal, e assim colaborar para a redução de taxas de crimes, para minorar a impunidade e, consequentemente, melhorar a qualidade de vida da população.

\section{PERFIL GEOGRÁFICO (GEOGRAPHIC PROFILING)}

Em meados da década de 1980, cientistas que ajudavam as investigações policiais (KIND, 1999; CANTER, 1994, 2004; ROSSMO, 1995) perceberam que poderiam estimar onde um infrator provavelmente se basearia em uma análise das localizações geográficas dos crimes desse infrator. Este processo de indicar a possível área em que a polícia deve procurar um ofensor acabou por ser conhecido como "perfil geográfico" (geographical profiling) (CANTER, 2004), ou na América do Norte (geographic profiling) (ROSSMO, 1995).

Geographic profiling, ou perfil geográfico, é o processo de determinação da área mais provável de se encontrar a base de atividades de um criminoso através dos locais de cometimento de crime (ROSSMO, 1999).

Segundo Paulsen e Robinson (2004), embora Le Beau em 1986 reconhecesse o potencial investigativo da análise geoestatística e da pesquisa de padrões de crime para reduzir as áreas de pesquisa de criminosos, não foi até 1990 que o verdadeiro perfil geográfico foi desenvolvido. 0 indivíduo mais reconhecido como responsável pelo desenvolvimento de perfis geográficos é $\mathrm{D}$. Kim Rossmo, ex-inspetor do Departamento de Polícia de Vancouver, no Canadá, que possui um PhD em Criminologia da Universidade Simon Fraser (Simon Fraser University School).

Dentre as iniciativas pioneiras documentadas na realização de procedimentos para fazer inferências sobre a base operacional dos infratores tem-se a descoberta relatada pela primeira vez por Canter e Gregory (1994) para estupradores em série, de que a casa ou a base de um infrator era, na maioria das vezes, inferida a partir da distribuição geográfica de suas ofensas. Naquela época, uma grande quantidade de publicidade estava sendo dada às contribuições que alguns agentes do FBI estavam reivindicando sobre como eles resolveram crimes, recorrendo a um processo que eles chamaram de "perfil de infração". Quando as deduções sobre onde um ofensor pode ser encontrado foram

$\begin{array}{lllll}\text { Caminhos de Geografia } \quad \text { Uberlândia-MG } & \text { v. 21, n. } 74 \quad \text { Abr/2020 } & \text { p. 51-67 } & \text { Página } 52\end{array}$


derivadas da distribuição de infrações em um mapa, pareceu apropriado chamar esse processo de "perfil geográfico".

Kind (1987) foi provavelmente a primeira pessoa a reconhecer o potencial de investigação da análise geográfica dos locais de crime. Em 1980, ele produziu um relatório sobre a localização dos crimes atribuídos a "The Yorkshire Ripper" que, durante um período de cinco anos a partir de julho de 1975, no norte da Inglaterra, havia assassinado 13 mulheres. Como um ex-navegador da Royal Air Force (RAF), Kind (1999) viu a tarefa de localizar o infrator como uma tarefa de navegação, comparando os locais de ofensa para depósitos de combustível, com o desafio de descobrir a localização ideal da base de uma aeronave ao calcular o "centro de gravidade" dos locais do crime. Isso se mostrou razoavelmente preciso ao determinar onde o condenado, Peter Sutcliffe, finalmente foi encontrado e preso antes que o relatório pudesse ser concluído. Então, a descoberta de Kind ficou adormecida até Canter redescobri-la cinco anos mais tarde (CANTER e YOUNGS, 2008).

Kind mostrou que a pequena distância média percorrida por muitos infratores é apenas um aspecto do comportamento espacial criminoso que possibilita a criação de perfis geográficos. Ele apresentou o segundo aspecto importante do comportamento espacial criminal, ou seja, a possibilidade de que muitos infratores tenham uma base dentro da área circunscrita por seus crimes. Isso mostrou ser um achado bastante distinto da pouca distância entre o lar e o crime (CANTER et al., 2000). De fato, a descoberta de que os criminosos tendem a operar em um determinado tamanho da área, tendo um "alcance criminal" particular (CANTER e GREGORY, 1994) ajudaram a ampliar a perspectiva inteira para além de apenas os infratores que viajam pequenas distâncias. Abriu o caminho para considerando os padrões de ofensa em relação à casa em vez de, simplesmente, se concentrar em infratores cuja base é próxima do crime. Esses padrões espaciais de ofensas, notadamente, o significado do lar, chamando a atenção para os processos psicológicos e perceptivos ambientais que tiveram que estar envolvidos no comportamento espacial criminal e a faixa característica de ofensa, levaram ao reconhecimento de que, em algumas circunstâncias, a base do criminoso poderia ser inferida com um grau de precisão útil de cálculos geométricos relativamente simples. Isso encorajou o desenvolvimento de sistemas de software - Crime Stat, Dragnet, Rigel e Predator, por exemplo -, que permitiram que as previsões fossem feitas e testadas, aplicando vários modelos geométricos às distribuições de crimes (ROSSMO, 1995; CANTER e YOUNGS, 2008).

Esses estudos iniciais demonstraram que os padrões de localização da ofensa eram relativos e precisavam ser ajustados, para a escala sobre a qual o agressor operava. Foram encontrados padrões muito semelhantes para os infratores que viajaram grandes distâncias para aqueles que viajaram por pequenas distâncias (CANTER, 2005). Isso significava que o perfil geográfico poderia ser muito mais do que apenas chamar a atenção para muitos infratores que têm bases próximas aos seus crimes. Poderiam derivar-se modelos mais amplos de infração, que explorassem os padrões geográficos independentemente do alcance de qualquer infrator (CANTER e YOUNGS, 2008).

A metodologia é baseada no modelo que descreve a caçada criminal. O comportamento de caça refere-se a processos de busca e ataque de vítimas por um ofensor, e os locais de destino são os vários locais geograficamente conectados por uma série de crimes. Os padrões e métodos da atividade de caça de infratores são analisados a partir de uma perspectiva geográfica da criminalidade. Ao estabelecer esses padrões, é possível delinear, através da análise dos locais dos crimes, a área mais provável de residência do agressor (ROSSMO, 1999).

A base conceitual dessa relação é fornecida pelo modelo de seleção de local de crime de Brantingham e Brantingham, que observam que indivíduos, incluindo criminosos, não se movem aleatoriamente através de seu ambiente. Na pesquisa de Brantingham e Brantingham, os pesquisadores utilizam o conhecimento sobre a atividade espacial do criminoso para predizer onde ele irá cometer crimes. O perfil geográfico (geographic profiling) essencialmente toma essas ideias e as inverte (PAULSEN e ROBINSON, 2004).

A pesquisa conduziu a um algoritmo para predizer a residência do criminoso da geografia do local do crime. O sistema computacional resultante produz superfícies de risco - superfícies de probabilidade tridimensionais que indicam a área mais provável de residência do agressor. Estes são exibidos através da produção de mapas isopléticos coloridos que fornecem um foco para os esforços de investigação (ROSSMO, 1999).

O perfil geográfico pode ser utilizado como uma base de várias estratégias investigativas, incluindo priorização de suspeitos (com base nos resultados, suspeitos que vivem nas áreas com maior probabilidade podem receber um foco investigativo adicional); busca de endereços baseada nos 
sistemas de registros policiais; saturação de patrulhamento (patrulhas policiais podem ser incrementadas nos locais onde se pensa que o infrator reside ou procura por vítimas); investigações na vizinhança (porta em porta); buscas por DNA (perfil geográfico pode ser utilizado para estreitar listas de indivíduos requeridos para serem submetidos a exames de DNA, reduzindo os custos associados a estes testes).

Deve ser considerado como uma das várias ferramentas disponíveis para investigadores criminais, e melhor empregado em conjunto com outros métodos policiais. Os padrões de criminalidade geográfica são rastros que, quando devidamente decodificados, podem ser usados para apontar a direção do ofensor (ROSSMO, 1999).

\section{METODOLOGIA}

\section{Base de dados}

A base de dados utilizada para o trabalho foi composta por Registros de Evento de Defesa Social (REDS) com delimitação espacial no município de Belo Horizonte no período de 01/01/2011 a $31 / 12 / 2013$, perpetrados por autores com no mínimo quatro boletins registrados como autores de delito.

Para cada autor de delito foi atribuído um código numérico sequencial, a fim de suprimir a identidade pessoal.

Para se atingir os objetivos propostos nesta pesquisa, foram coletados os seguintes dados:

a) número de criminosos habituais: 114 indivíduos;

b) ocorrências perpetradas por criminosos habituais: 1259 ocorrências;

c) endereços dos criminosos em série: 317 pontos;

d) ocorrências com locais de residência válidos para verificação se na área de acerto proposta pelo Perfil Geográfico contempla a casa do autor: 993 ocorrências.

As tipologias criminais obtidas como corpo da pesquisa, pelos requisitos propostos, constam da tabela 1.

Tabela 1 - Frequência de eventos de criminosos em série por categoria (tipologia criminal) - Belo Horizonte - 2011 a 2013.

\begin{tabular}{l|c|c}
\hline \multirow{2}{*}{\multicolumn{1}{c}{ Categoria }} & \multicolumn{2}{c}{ Frequência } \\
\cline { 2 - 3 } & \multirow{2}{*}{ Absoluta } & Relativa \\
\hline Contra o Patrimônio & 796 & $63 \%$ \\
Entorpecentes (Uso) & 111 & $9 \%$ \\
Entorpecentes (Tráfico) & 98 & $8 \%$ \\
Contravenção Penal & 94 & $7 \%$ \\
Contra a Liberdade Individual & 61 & $5 \%$ \\
Lesões Corporais & 37 & $3 \%$ \\
Contra a Administração & 21 & $2 \%$ \\
Armas & 9 & $1 \%$ \\
Contra a vida & 8 & $1 \%$ \\
Crime Trânsito & 8 & $1 \%$ \\
Fraude & 7 & $1 \%$ \\
Residual & 9 & $1 \%$ \\
\hline TOTAL $^{*}$ & $\mathbf{1 2 5 9}$ & $\mathbf{1 0 0 \%}$ \\
\hline
\end{tabular}

Fonte - Dados da Pesquisa. Nota: * Categoria Residual contempla (quatro eventos contra a Fé Pública; três eventos contra o Meio Ambiente; um evento contra a Honra e um evento de periclitação da vida).

Para a coleta dos locais de residência, foi feita a pesquisa das ocorrências do endereçamento dos autores de delito. Considerando-se que este parâmetro não possui georreferenciamento no próprio boletim de ocorrência, a inserção dos dados de coordenadas geográficas destes locais foi feita manualmente, buscando-se o georreferenciamento com precisão de quadra para os endereços válidos, utilizando-se a base de arruamentos e endereços da Empresa de Informática e Informação do Município de Belo Horizonte (PRODABEL) em SIRGAS.

$\begin{array}{lllll}\text { Caminhos de Geografia } & \text { Uberlândia-MG } & \text { v. } 21, \text { n. } 74 & \text { Abr/2020 } & \text { p. 51-67 Página } 54\end{array}$


Para os indivíduos em que havia algum endereço inválido, mas com outro boletim de ocorrência registrado em endereço diverso, excluiu-se o endereço inválido. Para os endereços indicados dos autores fora de Belo Horizonte utilizou-se a base Google para geocodificação.

Das 1259 ocorrências analisadas, 993 possuíam endereços válidos para as residências dos autores, sendo 307 domicílios para os 114 autores. Desta feita, alguns autores possuíam endereços distintos cadastrados em boletins de ocorrência diferentes, em 113 boletins de ocorrência os autores de delito não informaram o endereço e 153 (12\% do total de eventos) eram moradores de rua, não possuindo residência fixa.

\section{Técnica Perfil Geográfico}

Para se realizar uma análise preditiva da base operacional de agentes reincidentes e fazer uma comparação com os locais de residência, utilizou-se a técnica de Perfil Geográfico. Para tanto, foi utilizado o software Rigel Workstation 2.1, em sua versão Demo, com licença de uso disponibilizada via acesso remoto ao servidor pela Empresa ECRI Canada.

O resultado do perfil geográfico produz um mapa de probabilidade (raster-grid) que mostra a probabilidade da base de origem estar localizada em cada célula da grade no mapa, conforme exemplo da Figura 1.

Figura 1 - Demonstração de Resultado do Geographic Profiling pelo software Rigel.

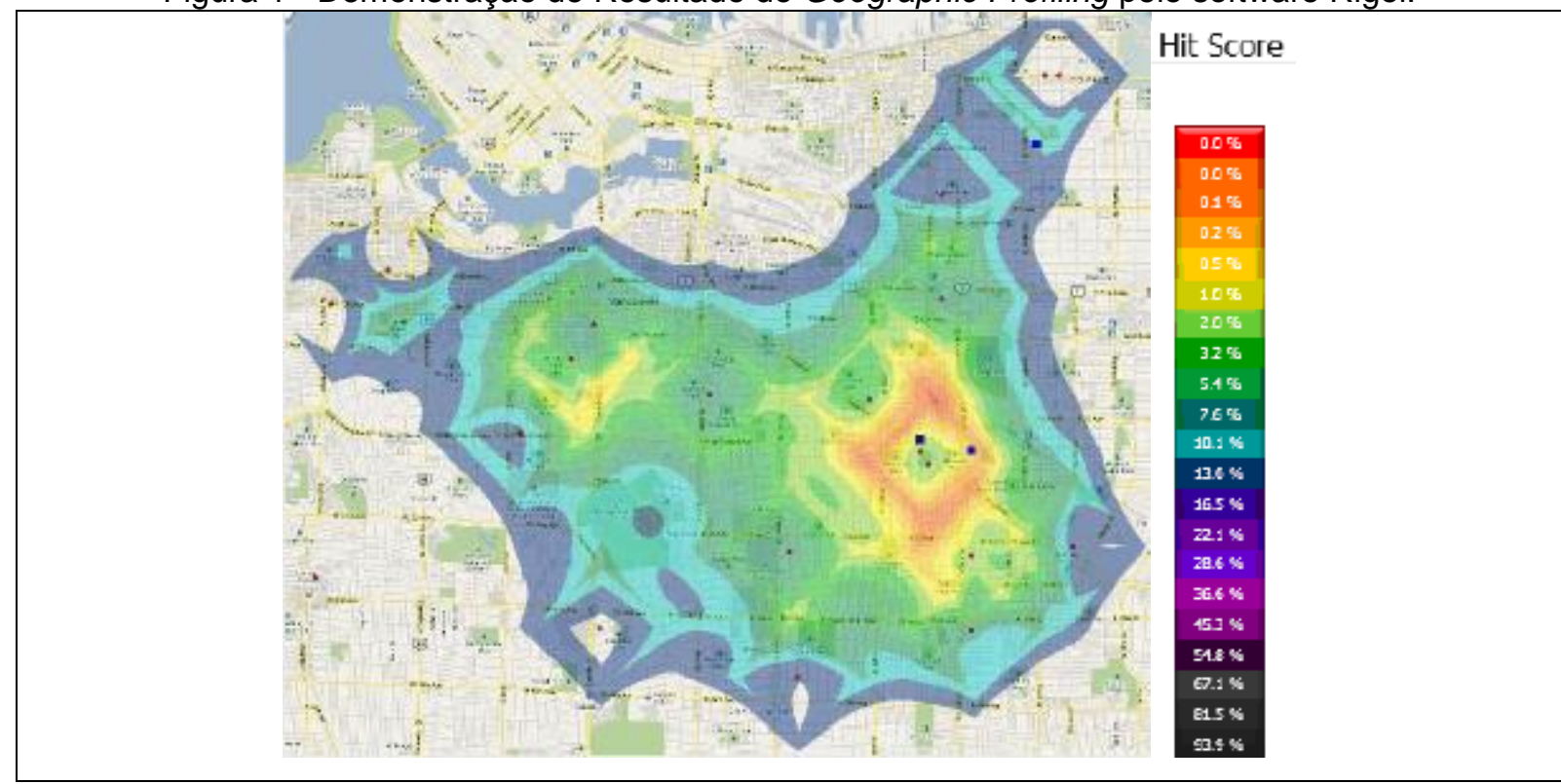

Fonte - ECRI (2012).

Este mapa é chamado de perfil geográfico, ou simplesmente geoprofile. É representado como um mapa de cores no qual a cor corresponde ao escore que define a probabilidade de se encontrar a base operacional do autor de delitos.

\section{Pressupostos do modelo de análise de perfil geográfico}

O modelo central é que, para cada crime, o agressor se propõe a partir de sua base em busca de um alvo ou vítima adequado e comete um crime onde ele encontra um. Conforme ECRI (2012), os elementos essenciais desse modelo são:

a) o infrator tem uma única base de casa (home base) estável ao longo da série de crimes;

b) para cada crime, o infrator encontra seu alvo ou vítima em uma busca geográfica originária dessa base;

c) o infrator comete o crime onde ele encontra seu alvo ou vítima. 
Caso o infrator tenha mais de uma base, a partir da qual comete seus crimes, ou há mudança na base de operações durante a série de crimes, isso irá distorcer e potencialmente invalidar o perfil geográfico. Não obstante, em alguns casos, pode ser possível distinguir que há mais de uma base no padrão do perfil, por exemplo, se houver uma base distinta para os crimes iniciais em uma série e uma base distinta diferente para os crimes posteriores (ECRI, 2012).

Outra premissa para aplicação do modelo de perfil geográfico é que o infrator realize sua busca movendo-se no ambiente físico (pesquisa geográfica). Logo, se o infrator não realiza a busca geográfica por destinos (por exemplo, se a busca por alvos ou vítimas potenciais via internet ou em anúncios de jornal, a busca não é geográfica), o perfil geográfico não é aplicável (ECRI, 2012).

$\mathrm{O}$ ambiente que é cenário onde os crimes ocorrem também deve ser uniforme (uniform target backcloth). Ou seja, se os alvos são raros ou distribuídos de forma muito desigual, isso pode distorcer ou invalidar o perfil geográfico com base nesses locais. Por exemplo, se um estuprador em série atacar prostitutas que são todas apanhadas em um pequeno distrito, o pano de fundo para os locais de encontro é muito não uniforme. No entanto, os locais de distribuição de vítimas podem ser mais distribuídos e mais significativos (ECRI, 2012).

O modelo utilizado por ECRI (2012) baseia-se no fato que o infrator faz sua jornada na busca por alvos a partir de sua base e regressa à sua base entre os crimes em série (journey from home base). Se o infrator não viajar de sua base para o local do crime, para cada um dos crimes, a base para um perfil geográfico está faltando. Por exemplo, se um ofensor faz uma longa viagem e comete delitos em várias paradas ao longo do caminho, os crimes individuais não representam cada um como uma jornada independente da base. Este seria um exemplo do que se chama no direito penal brasileiro de crime continuado, descrito no artigo 71 do Código Penal Brasileiro (BRASIL, 1940).

No caso deste trabalho, todos os eventos são independentes, havendo registros para cada um e que foram cometidos em datas diferentes, não ocorrendo esta situação de crime continuado no banco de dados utilizado para a pesquisa.

O modelo utilizado por ECRI (2012) assume que a infração é cometida quando o alvo ou vítima é encontrado. Mesmo que o alvo ou vítima seja encontrado no decurso de uma pesquisa proveniente da base doméstica, se o crime não ocorrer lá, pode não haver base para um perfil geográfico dos locais do crime. Assim, se o infrator segue as vítimas após encontrá-la no caminho, o local do crime não é o mesmo de encontro. Desta forma, o local (onde) é mais importante na análise que o momento (quando), pois os infratores se lembram dos locais para encontrar potenciais alvos para futuros crimes.

Um pressuposto chave é que todos os incidentes que estão sendo perfilados estão corretamente vinculados ao mesmo infrator. Embora alguma incerteza e erro possam ser tolerados, um número significativo de erros de ligação pode enfraquecer ou distorcer o geoprofile. A análise de ligação (linkage analysis) é, portanto, um importante precursor do perfil geográfico. O treinamento em análise de ligação e o uso de ferramentas disponíveis para verificação de ligação são recomendados para analistas de perfil geográfico (ECRI, 2012). Para este trabalho, todos os eventos analisados para cada caso são cometidos por um mesmo autor, não havendo, portanto, risco deste erro de vínculo.

Outro aspecto relevante é a completude da série de eventos. Em alguns casos, a série de crimes que está sendo perfilada pode estar incompleta, por motivos que incluem a subnotificação (cifra negra), a não divulgação de informações, análise de vínculos precária ou período histórico insuficiente. Os crimes que faltam tornam-se um problema quando resultam em uma predisposição/tendência geográfica, o caso quando somente uma parcela de crimes é registrada (uma jurisdição notifica os casos enquanto outra não o faz, o que torna a análise tendenciosa).

\section{Etapas da análise de perfil geográfico realizada no software RIGEL}

O processo de análise de perfil geográfico adota pela ECRI no software RIGEL segue o fluxo descrito na Figura 2. 
Figura 2 - Processo de análise de perfil geográfico para crimes reincidentes conforme ECRI/RIGEL.

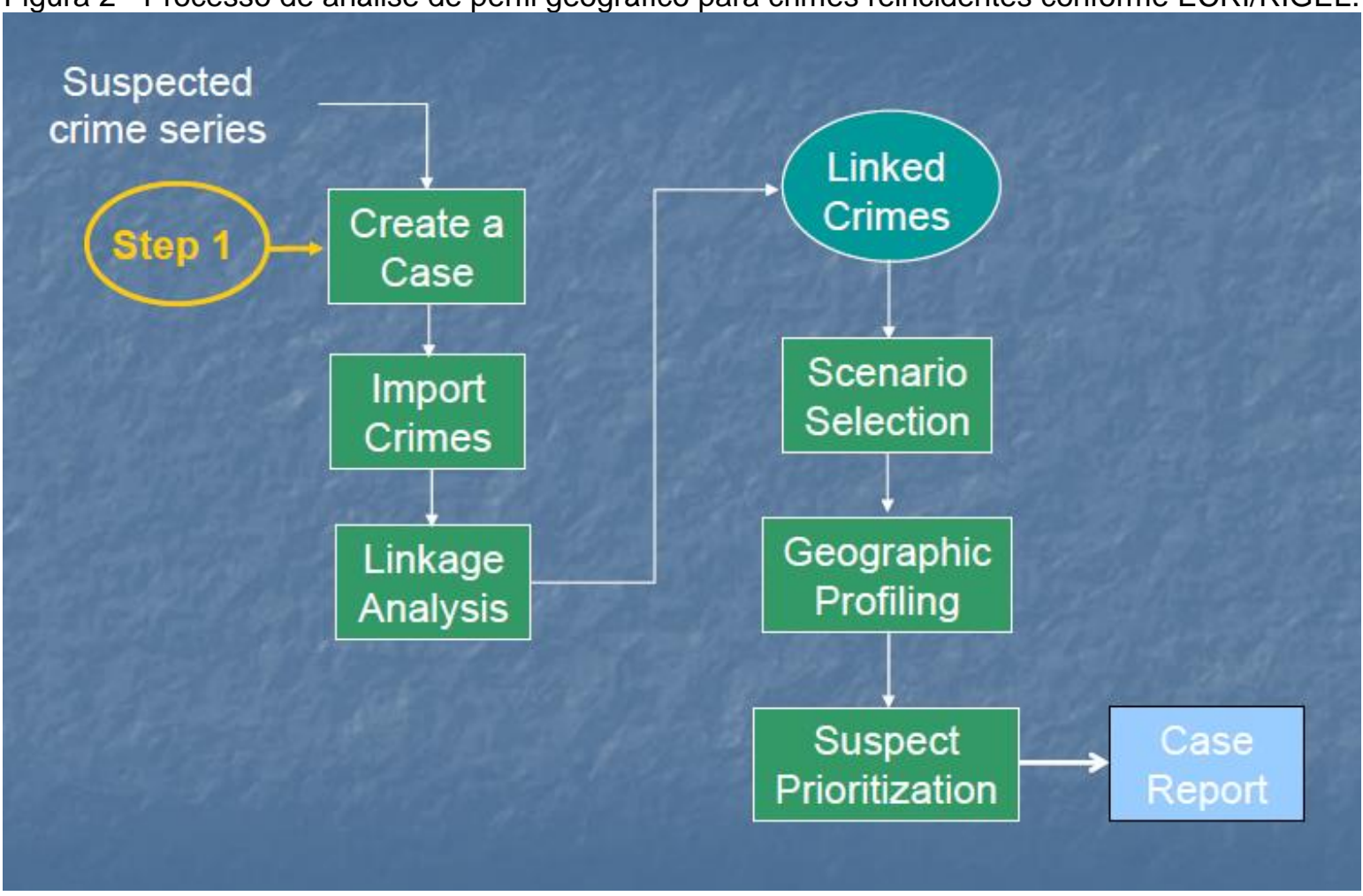

Fonte - ECRI (2012).

Os passos básicos para realização do perfil geográfico são:

a) identificação de série vinculada de crimes (linkage analysis);

b) construir um cenário com o melhor conjunto de locais de crime para o perfil geográfico;

c) calcular o perfil geográfico conforme algoritmo do sistema e avaliar os resultados;

d) identificar a área de perfil máximo e priorizar a lista de suspeitos;

e) sugerir possíveis estratégias de investigação com base no perfil.

O primeiro passo é a criação dos casos para análise. Para o presente trabalho foi criado um "caso" para cada autor reincidente, contendo, em cada "caso", todos os eventos identificados para o autor.

O próximo passo reside na realização de análise de vínculos. Para o trabalho, não foi necessário realizar a análise de vinculação (linkage analysis), pois a premissa da pesquisa consistia na elaboração do banco de dados contendo as ocorrências definidas por autor reincidente. Logo, todos os eventos são séries de crimes cometidos por um único agente.

Na sequência tem-se a definição do "cenário". Segundo ECRI (2012), o cenário é um subconjunto de todos os crimes incluídos no caso e representa uma teoria sobre quais crimes são os melhores para análise. O conjunto completo de crimes é chamado de cenário de "caso base". O principal motivo para desenvolver um cenário em vez de usar todos os crimes é que alguns crimes devem ser excluídos porque eles não se encaixam no modelo ou violam uma suposição.

$\mathrm{Na}$ seleção de cenário, é aplicado um conjunto de regras com base no modelo subjacente de viagens de infrator e seleção de locais de crimes. O cenário deve incluir apenas crimes que representam jornadas independentes para o local do crime, a partir da base de pesquisa comum. Algumas das regras de tempo e distância são verificadas automaticamente pelo Expert System no software, enquanto outras exigem o conhecimento humano do analista. No caso deste trabalho, os cenários foram criados a partir do Expert System.

Os eventos que não se enquadram nos parâmetros são denominados outliers. Os outliers são crimes que não se enquadram no padrão normal observado na série. Eles poderiam estar muito distantes dos outros crimes no espaço ou no tempo, ou poderiam representar algum outro tipo de comportamento anômalo. Assim, os outliers devem ser excluídos do cenário usado para o perfil geográfico (Figura 3). 
Figura 3 - Representação do cenário utilizado para análise Geoprofile.

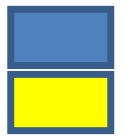

Área que contempla total de eventos

Cenário

- Crimes considerados na análise

- Outliers

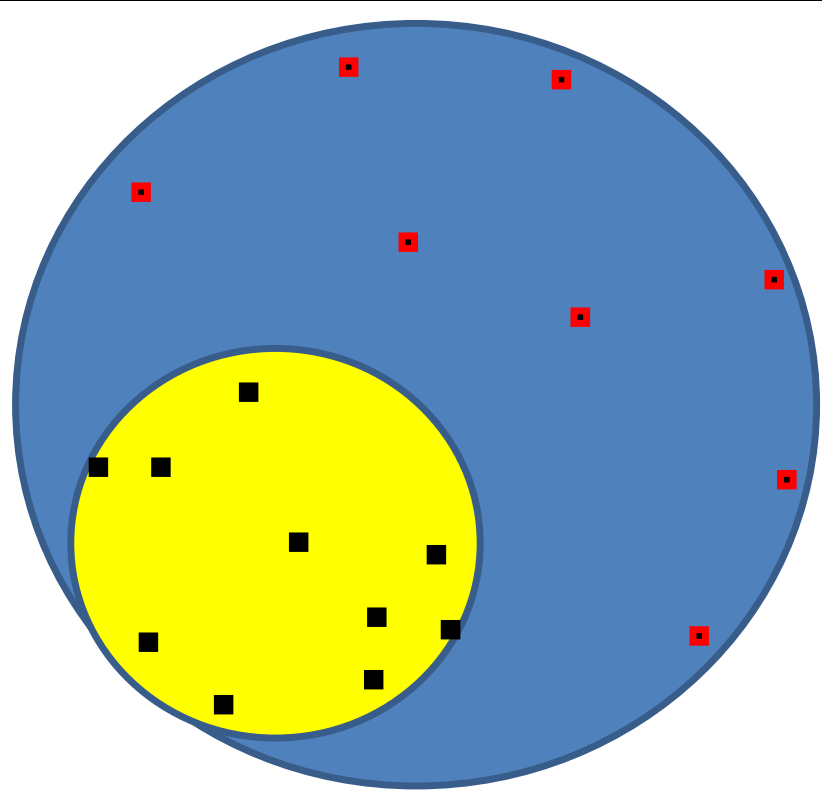

Fonte - Elaborado pelos autores a partir de ECRI (2012).

É necessário que as viagens para o crime sejam independentes. No caso de viagens não independentes, por exemplo, se vários crimes estiverem muito próximos uns dos outros no espaço e/ou no tempo, eles não podem representar uma viagem independente da base do local do crime (por exemplo, uma série de pequenos incêndios criminosos em uma noite numa mesma rua). Neste caso, apenas um crime do grupo deve ser incluído no cenário, de preferência o local inicial ou, se o ponto inicial não puder ser determinado, deve ser incluído aquele que maximiza a disseminação espacial e temporal do cenário (ECRI, 2012). A Figura 4 esquematiza o tratamento de dados para cálculo do geoprofile.

Figura 4 - Tratamento dado a viagens dependentes para cálculo do geoprofile.

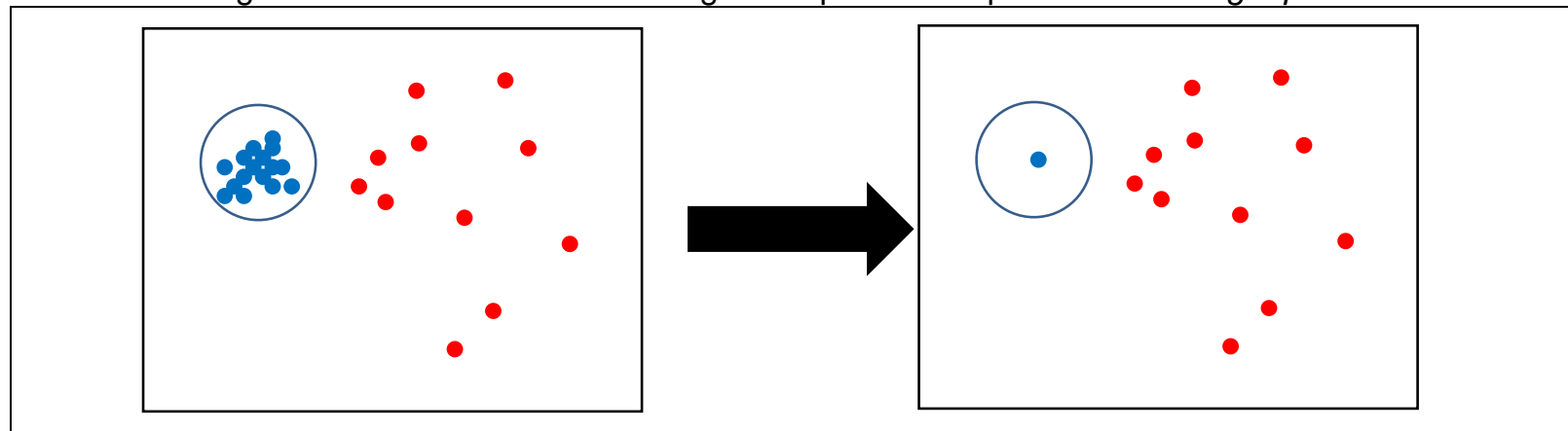

Fonte - Elaborado pelos autores a partir de ECRI (2012).

Quanto aos tipos de locais, se um caso incluir vários tipos de locais, cada tipo pode representar um tipo diferente de viagem e até mesmo uma base doméstica diferente. Os cenários podem ser usados para analisar os diferentes tipos de locais separadamente. Por exemplo, um autor de homicídios em série provavelmente usa critérios diferentes para onde descartar um corpo do que encontrar uma vítima. Os locais de encontro de vítimas e os de despejo de corpos, por exemplo, geralmente devem ser perfilados separadamente, mesmo que estejam ligados ao mesmo ofensor e ofensas. 


\section{Resultados}

Os resultados do Geoprofiling são exibidos na forma de números e gráficos na janela Geoprofile Summary (Resumo do Geoprofile), e o próprio geoprofile é mostrado como uma camada no mapa com pontuações $Z$ coloridas de acordo com a legenda, conforme exemplo da Figura 5.

Figura 5 - Exemplo de resultados de Geoprofile obtidos pelo software RIGEL.

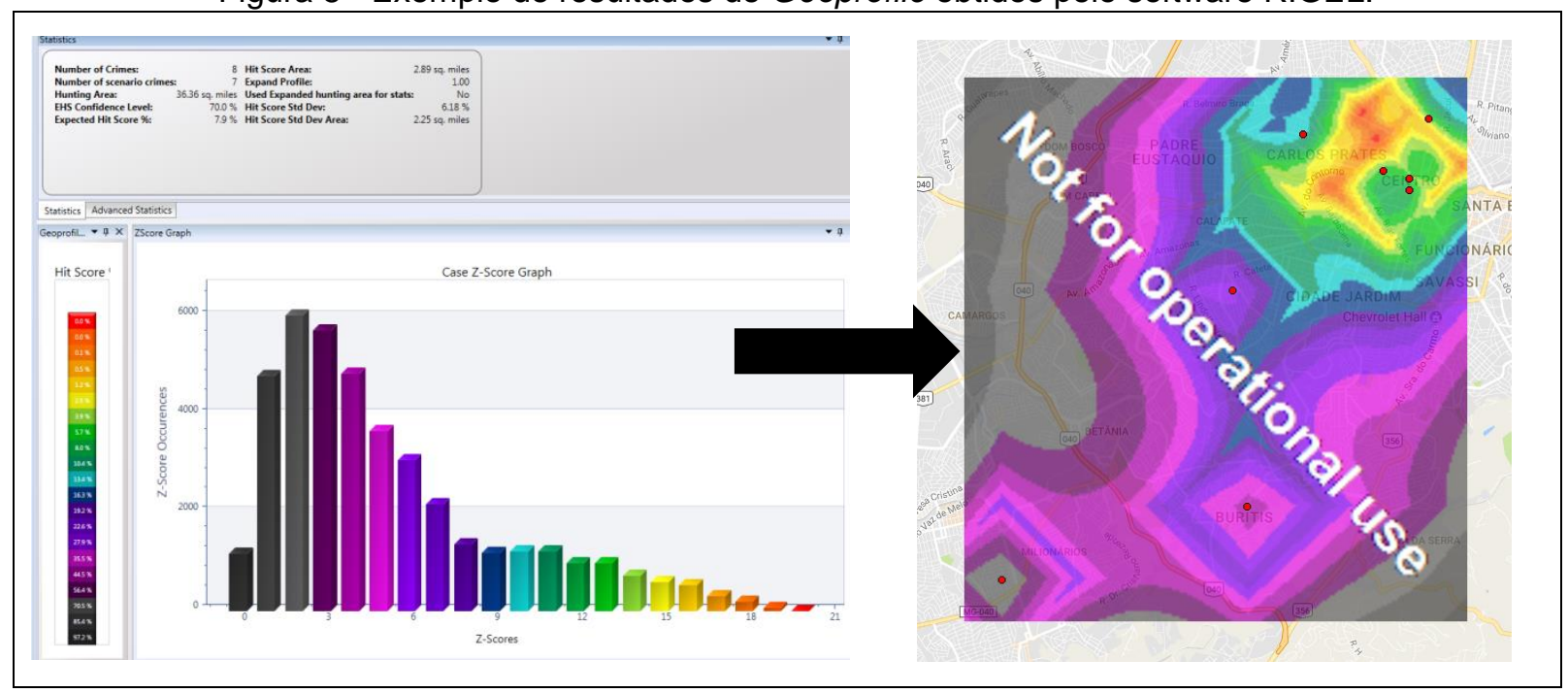

Fonte - Elaborado pelos autores no software RIGEL.

Quanto maior a pontuação Z para qualquer célula da grade, mais provável é que a base de pesquisa do infrator esteja naquela célula da grade.

Além da representação do mapa isoplético, com as áreas de probabilidade de se encontrar a base de operações dos autores de crimes, o software RIGEL, por meio do algoritmo de Criminal Geographic Targeting (CGT), que usa sobreposição de funções de decaimento com a distância, centradas em cada local de crime para produzir superfícies de risco (jeopardy surface), que são superfícies de probabilidade tridimensionais que indicam a área onde $o$ infrator provavelmente pode ser encontrado (domicílio/base de operações). A Figura 6 traz um exemplo de representação da superfície de risco.

Figura 6 - Exemplo de resultados de superfície de risco (Jeopary surface) de se encontrar o autor dos delitos seriados obtidos pelo software RIGEL.

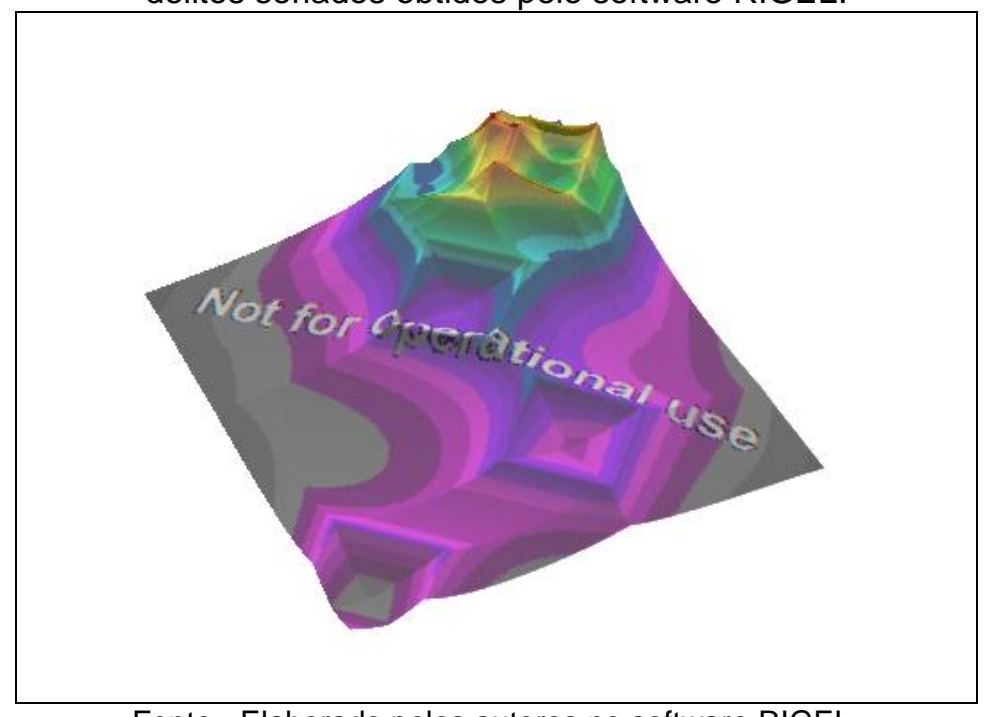

Fonte - Elaborado pelos autores no software RIGEL. 


\section{Algoritmo utilizado pelo sistema no cálculo do Perfil Geográfico}

O software Rigel utiliza do algoritmo Criminal Geographic Targeting (CGT) de Kim Rossmo, o qual é baseado no modelo de Brantingham e Brantingham desenvolvido na década de 1980 a partir da observação do comportamento de decaimento com a distância (BRANTINGHAM; BRANTINGHAM, 1981, 1984) e a abordagem de atividades rotineiras (FELSON, 1986).

Conforme Rossmo (1995, p. 224), o modelo é baseado em um processo de quatro etapas:

a) os limites do mapa delineiam a área de caça (busca) do infrator, que são estabelecidos inicialmente usando os locais dos crimes e procedimentos padrão para abordar os efeitos de borda;

b) distâncias de Manhattan (distâncias ortogonais) são calculadas de cada "ponto" no mapa a cada local do crime, cujo número é determinado pela resolução de medição das escalas $x$ e y.

c) em seguida, essas distâncias Manhattan são usadas como valores de variáveis independentes em uma função que produz um número que: (a) se o ponto estiver fora da zona de buffer, torna-se menor, quanto maior a distância, seguindo alguma forma de decaimento com a distância; ou (b) se o ponto estiver dentro da zona de buffer, torna-se maior se a distância for maior. Os números são calculados a partir desta função para cada um dos locais do crime. Por exemplo, se houver 12 locais de crime, cada ponto no mapa terá 12 números associados a ele.

d) finalmente, esses múltiplos números são multiplicados para produzir uma única pontuação (score) para cada ponto do mapa. Quanto maior a pontuação resultante, maior a probabilidade de o ponto conter a residência do agressor.

O algoritmo CGT faz uso de uma função de pontuação (scoring function) para segmentar áreas de pesquisa de alta prioridade, conforme Equação 1:

$S(y)=\sum_{i=1}^{n} f\left(d\left(x_{i}, y\right)\right)$

Na função, $y$ é uma localização na grade de busca, $d$ (xi; $y$ ) é a distância de $y$ para crimes da série, e $f$ é uma função de decaimento que simula o comportamento observado por Brantingham e Brantingham.

Dada uma série de crimes contendo $n$ eventos vinculados nas localidades $x_{1}=\left(x_{1} ; y_{1}\right), x_{2}=\left(x_{2} ; y_{2}\right), \ldots$, $x_{n}=\left(x_{n} ; y_{n}\right)$ em uma área de pesquisa discreta. O algoritmo CGT começa pela primeira determinação $d$ : distância média do vizinho mais próximo. As duas escolhas mais comuns para o interesse geográfico são: a distância euclidiana (em linha reta), descrita conforme Equação 2:

$$
d\left(x_{i}, x_{j}\right)=\sqrt{\left(x_{i}-x_{j}\right)^{2}+\left(y_{i}-y_{j}\right)^{2}}
$$

ou distância Manhattan, conforme Equação 3:

$$
d\left(x_{i}, x_{j}\right)=\left|x_{i}-x_{j}\right|+\left|y_{i}-y_{j}\right|
$$

O CGT mede a distância de cada distância de crime $x_{i}$ para os crimes $n-1$ restantes da série e registra a distância para o vizinho mais próximo. A média dessas distâncias vizinhas mais próximas é dada pela Equação 4: 


$$
\bar{d}=\sum_{i=1}^{n} \frac{\min _{j \neq i}\left(d\left(x_{i}, x_{j}\right)\right)}{|n|}
$$

Que será usada para determinar o raio da zona de buffer. O CGT determina a pontuação de acerto de pontos na área de busca usando a função de pontuação (scoring function) descrita na Equação 5:

$$
S(x . y)=k \sum_{i=1}^{n}\left(\frac{\phi}{\left(\left|x-x_{i}\right|+\left|y-y_{i}\right|\right)^{h}}+\frac{(1-\phi) B^{g-h}}{\left(2 B-\left|x-x_{i}\right|+\left|y-y_{i}\right|\right)^{g}}\right)
$$

Onde: $\mathrm{K}$ é uma constante de escala; $\mathrm{B}$ é o raio da zona de buffer, igual à metade da distância média mais próxima do vizinho; $h=g=1,2$ são constantes selecionadas de um modelo de gravidade desenvolvido para descrever padrões de migração de fugitivos criminosos (ROSSMO, 1987, 1995 apud ALLEMAN, s.d); e $\phi$ é um valor determinado pela função por partes, conforme Equação 6:

$\phi= \begin{cases}1, & \text { se }\left|x-x_{i}\right|+\left|y-y_{i}\right| \geq B \\ 0, & \text { se }\left|x-x_{i}\right|+\left|y-y_{i}\right|<B\end{cases}$

Conforme Alleman (s.d), o resultado é uma concentração de scores de alta pontuação (hit score) perto dos crimes da série. Com base nas métricas de distância escolhidas e no número de infrações, o mapa de pontuação de acerto (hit score map) variará, mas há uma área de busca bem definida, com picos em torno das zonas buffer em torno de cada crime. Os mesmos autores apresentam um exemplo de resultado do algoritmo CGT para uma série de roubo em Los Angeles, CA, conforme a Figura 7:

Figura 7 - Resultado do Algoritmo CGT para crimes em série em Los Angeles.

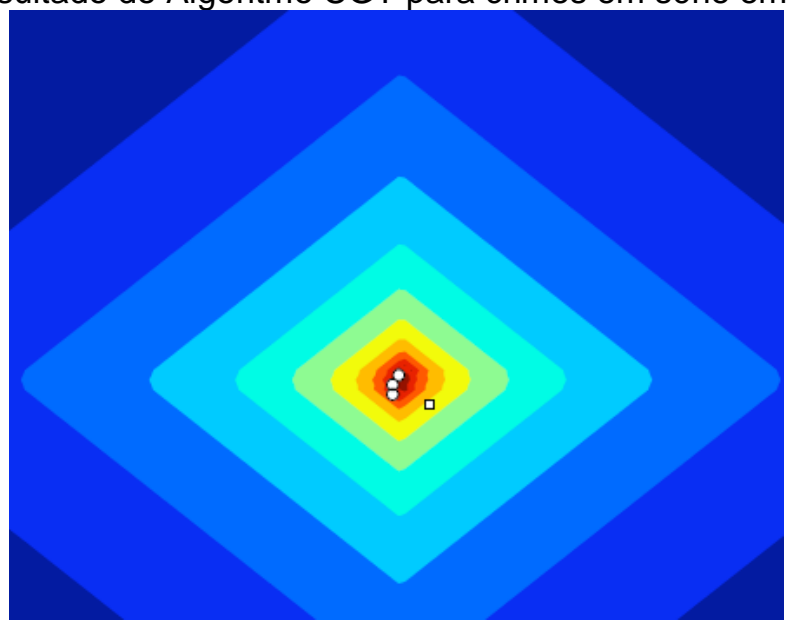

Fonte - Alleman (s/d, p. 238). Notas: Quadrado branco indica a base de operações do infrator (local de residência, espaço de trabalho do autor, etc.) Círculos brancos indicam os locais de crime.

\section{RESULTADOS E DISCUSSÕES}

A área de busca refere-se ao espaço que compreende os eventos utilizados para a formação do cenário de eventos em série, excluindo-se desses cenários os eventos identificados pelo Expert 
System do software como sendo outliers, os quais são crimes que não se enquadram no padrão normal observado na série, por estarem muito distantes dos outros crimes no espaço ou no tempo, ou por representarem algum tipo de comportamento anômalo. A área do raio de acerto representa a área em que se espera que a base operacional do agente habitual seja encontrada.

A porcentagem de pontuação de acerto (hit score percentage) é uma medida de eficiência de pesquisa de perfis geográficos. É definido como a proporção da área pesquisada (seguindo a priorização do perfil geográfico) antes que a base do infrator seja encontrada, para a área total de busca. Quanto menor este índice, melhor será o foco do geoprofile (ROSSMO, 2005).

A área de busca (hunting area) é definida como a zona retangular orientada ao longo da grade de rua contendo todos os locais de crime. Esses locais podem ser pontos de encontro de vítimas, cenas de assassinato, locais onde o corpo foi deixado ou alguma combinação de elementos e circunstâncias, conforme a inserção de dados no sistema. O termo área de busca é, portanto, usado amplamente no sentido da região geográfica dentro da qual o ofensor escolheu - após alguma forma de busca ou processo de caça - uma série de lugares para ação criminal. As localidades desconhecidas para as autoridades, incluindo aquelas em que o infrator procurou por vítimas ou locais de despejo, mas não tiveram sucesso ou optaram por não agir, obviamente não estão incluídas (ROSSMO, 2005).

Os dados reportados para cada indivíduo apresentam grande variação em relação principalmente à área de busca e área do raio de acerto. A menor área do raio de acerto encontrada foi de $0,0033 \mathrm{~km}^{2}$, a maior de $53,28 \mathrm{~km}^{2}$ e a média $4,76 \mathrm{~km}^{2}$.

No exemplo da Figura 8, verifica-se o geoprofile para um dos indivíduos, a fim de melhor compreender os resultados obtidos pelo método.

Figura 8 - Geoprofile do Indivíduo 01 (8 crimes no cenário).

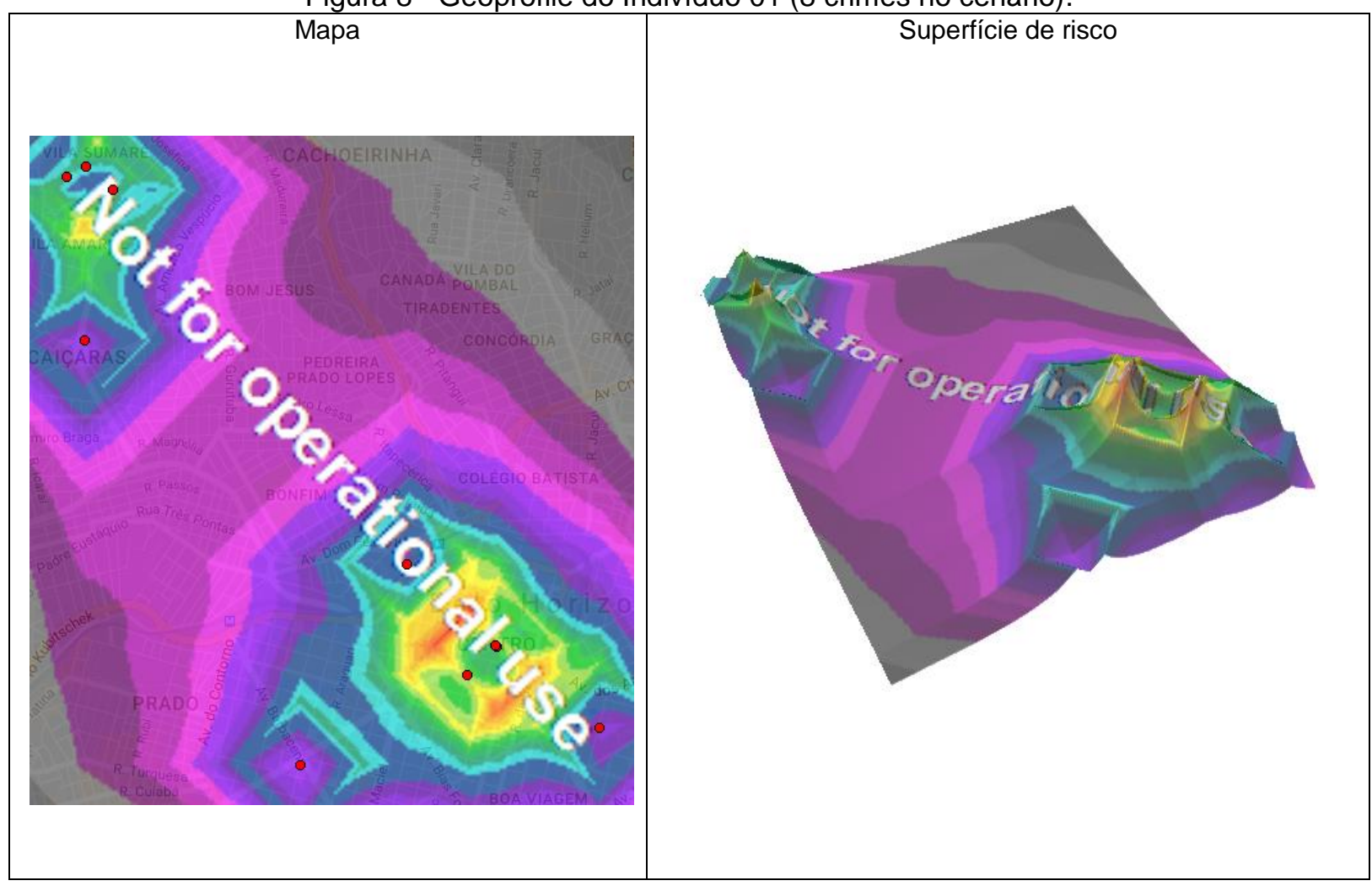




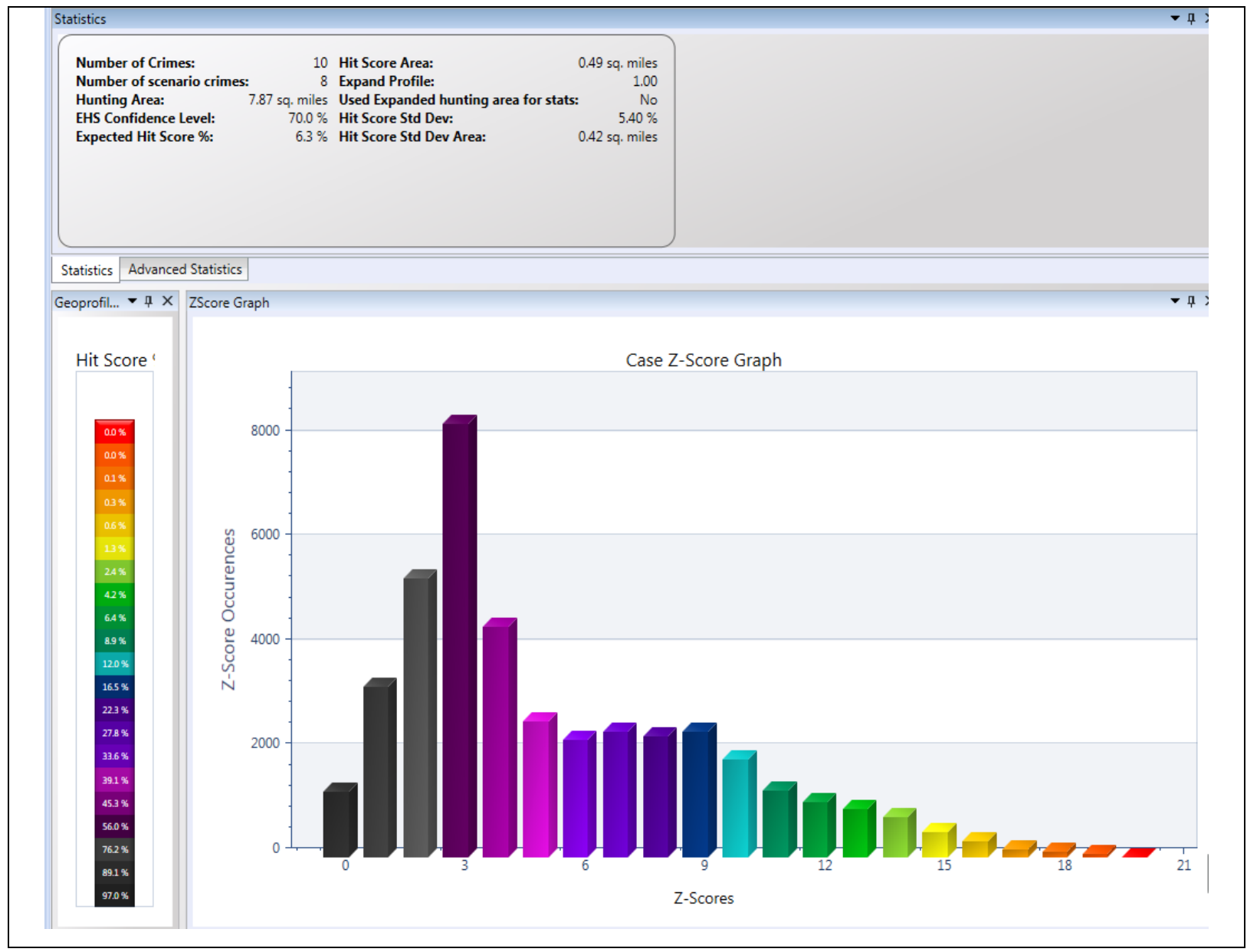

Fonte - Dados da Pesquisa.

Para o indivíduo 01, representado acima, de um total de dez crimes cometidos, oito compuseram o cenário analisado pelo software para o perfil geográfico. A área de busca para o caso foi de 20,38 $\mathrm{km}^{2}$, sendo a área do raio de acerto igual a $1,27 \mathrm{~km}^{2}$. Em termos práticos, a área de acerto é bem restrita em relação à dispersão dos eventos cometidos, o quer viabiliza subsidiar estratégias de investigação criminal que visem encontrar o autor dos delitos.

A medida mais apropriada do desempenho do perfil geográfico é "porcentagem de pontuação acertada / custo de pesquisa". É a proporção da área pesquisada (seguindo a priorização do perfil geográfico) antes da base do infrator, para a área total de busca. Quanto menor este índice, melhor será o foco do geoprofile. Não há desvantagens intrínsecas a esta medida.

O perfil geográfico é fundamentalmente uma forma probabilística de análise de padrões de pontos. Todo ponto adicional (ou seja, local de ofensa) em uma série de crime adiciona informações e resulta em maior precisão. Um mínimo de cinco locais de crime é necessário para a detecção de padrões estáveis e um nível aceitável de foco investigativo. A média em casos operacionais foi de 14 para os trabalhos descritos por Rossmo $(1999,2001)$. O teste de Monte Carlo mostra com apenas três crimes que a porcentagem de pontuação esperada é de aproximadamente $25 \%$. Em comparação, a área de pesquisa esperada cai para $5 \%$ com 10 crimes. A resolução de qualquer método será fraca se testada em séries de apenas alguns crimes (ROSSMO, 2005). Para o presente trabalho, para o qual se utilizou como mínimo de eventos para análise 04 ocorrências em série, a relação entre o raio de acerto e o número de eventos consta da Figura 9. 
Figura 9 - Relação entre o raio de acerto (hit score \%) e número de eventos para Geoprofile.

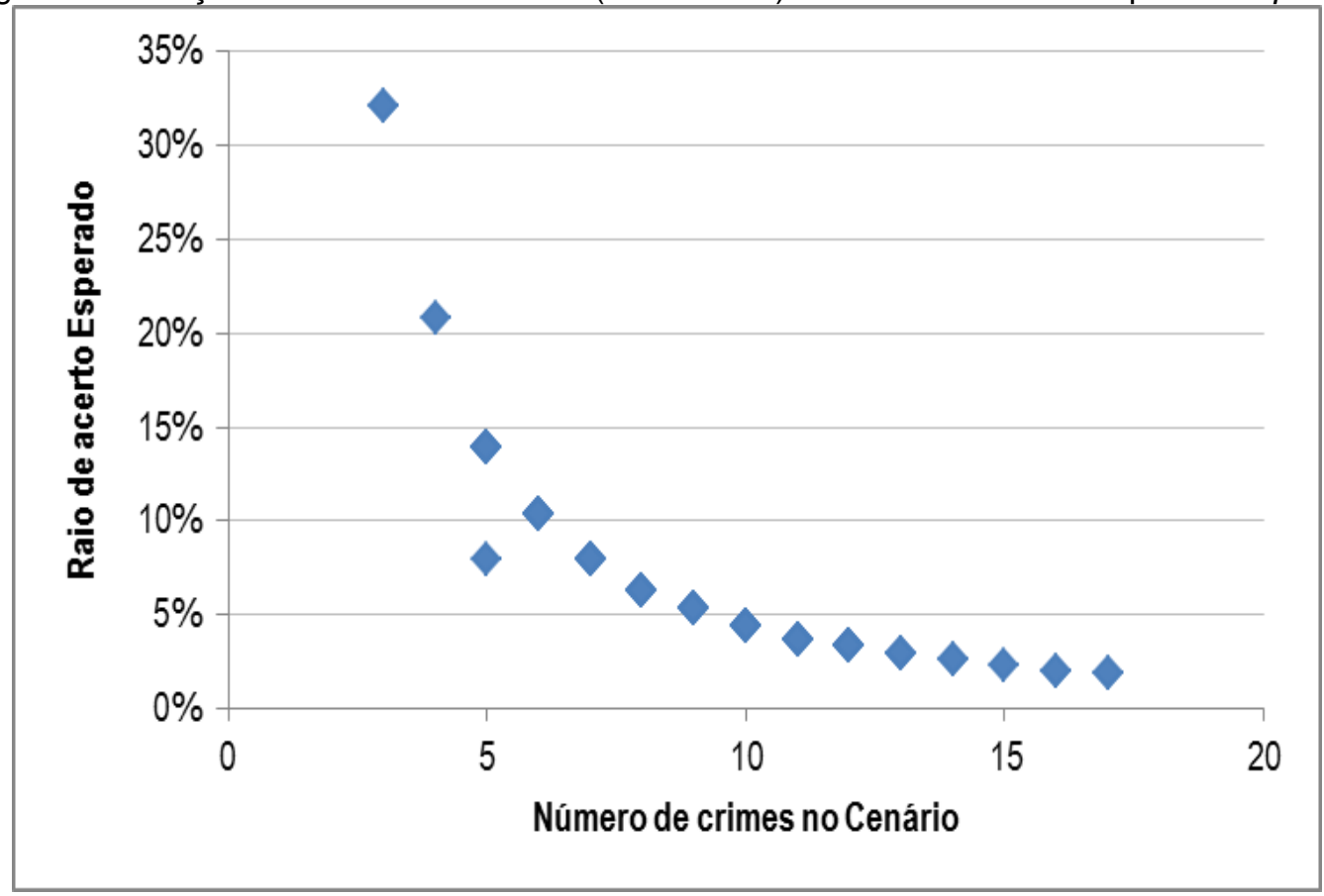

Fonte - Dados da Pesquisa.

A média de eventos analisados para o caso em Belo Horizonte é de 11 ocorrências, sendo que os dados obtidos para os perfis realizados corroboram com os obtidos por Rossmo (2005), sendo que quanto maior o número de eventos considerado para a realização do geoprofile (número de crimes no cenário), menor é o percentual do raio de acerto esperado (hit score \%) em relação à área pesquisada. Sendo esse um parâmetro para aferição da acurácia do software, então, quanto maior o número de eventos, melhor será a assertividade do método.

Assim, pode-se considerar que, pela média de eventos por cenário de 8,89 (nove eventos), há uma média de 6,94\% para o raio de acerto esperado, logo, há um bom índice de assertividade para o software utilizado com os dados da pesquisa, o que viabilizaria seu uso como ferramenta de apoio à atividade de inteligência.

Com a finalidade de verificar se os locais de residência indicados foram contemplados pelo perfil geográfico, foi feita a análise da assertividade prática da técnica em relação à residência enquanto possibilidade de base operacional dos indivíduos autores dos crimes. A seguir, na Figura 10, apresenta-se o exemplo do indivíduo 01 para a comparação realizada. 
Figura 10 - Comparação entre o perfil geográfico e localização dos endereços válidos indicados nos boletins de ocorrência (indivíduo 01).

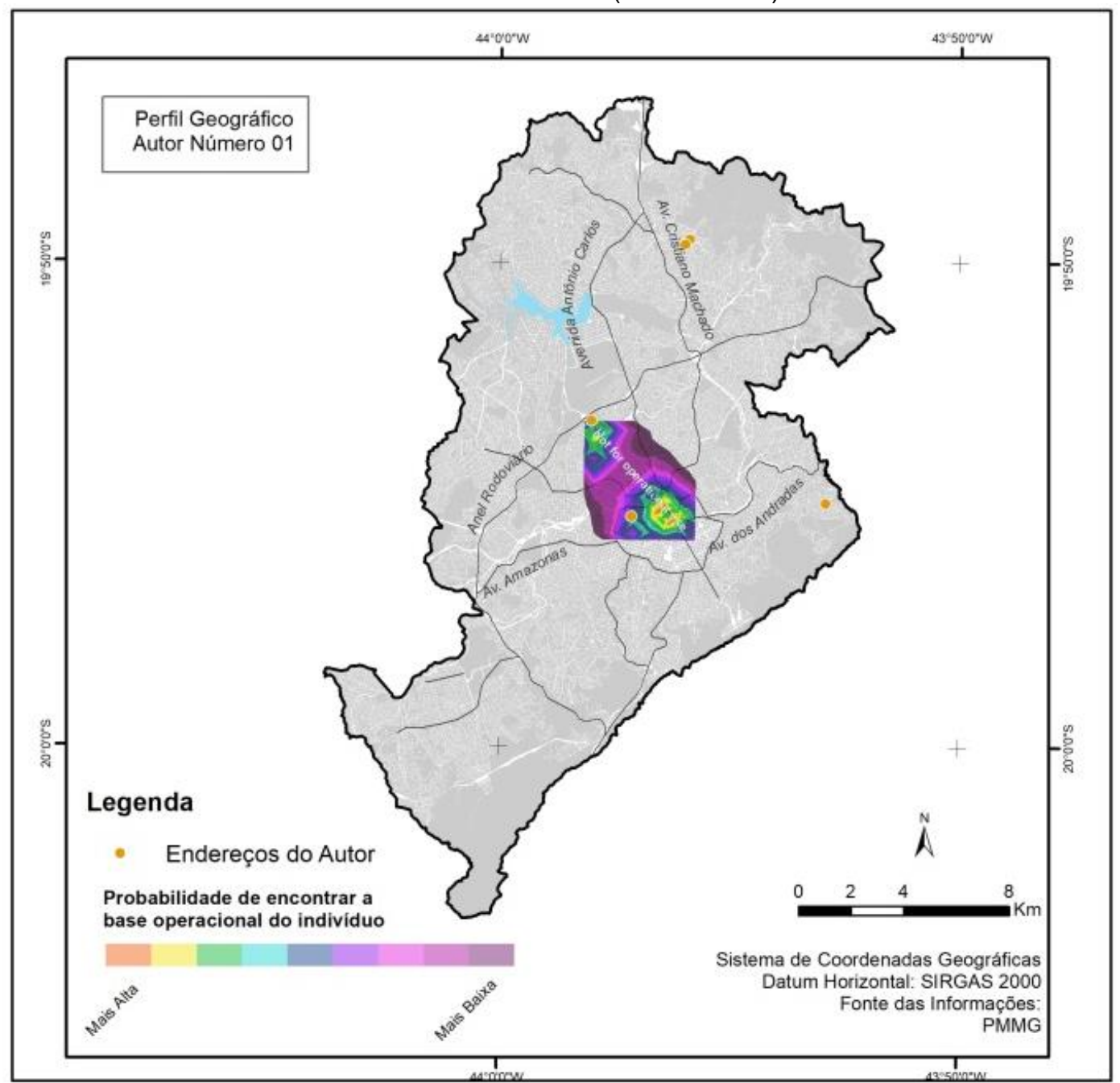

Fonte - Elaborado pelos autores.

Para o indivíduo 01, há dois endereços de endereço contemplados pelo perfil geográfico.

Obteve-se com resultados satisfatórios para 106 indivíduos, excluindo-se os indivíduos 11, 12, 37, 87, $95,106,118,126$, cujos eventos não atenderam os parâmetros para formação de cenários do algoritmo utilizado pelo software RIGEL.

Dos 106 perfis geográficos realizados, 90 indivíduos (85\% dos 106 processamentos) obteve-se pelo menos um endereço válido conhecido do infrator dentro da área de busca criada pelo RIGEL. Em que pese a residência não representar necessariamente um ponto de partida para a jornada que leva o infrator à cena do crime, essa possibilidade de encontrar o endereço fornece maiores subsídios para a busca de alvos em apurações de crimes seriados.

Em relação ao acerto de uma residência conhecida de infrator na área de acerto obtida pela utilização da técnica, obteve-se 56 casos ( $53 \%$ do total) com pelo um endereço conhecido dentro da área de acerto.

Considerando-se ainda que a área de acerto do mais da metade dos perfis geográficos criminais (64 casos) apresentou raio de acerto menor do que $2 \mathrm{~km}^{2}$, sendo esta área representada por uma quadrícula com dimensões de aproximadamente $1,414 \mathrm{~km}$, sendo uma porção territorial bem restrita, o que viabiliza a localização dos autores de delitos, além de ser compatível com estratégia de setorização do policiamento adotada por polícias ostensivas de preservação da ordem pública. 


\section{CONSIDERAÇÕES FINAIS}

Em relação ao perfil geográfico, processo de determinação da área mais provável de se encontrar a base de atividades de um criminoso, a partir dos locais de cometimento de crimes em série, foi possível verificar que essa técnica agrega informações sobre os locais onde se pode encontrar o infrator nos possíveis nós e trajetos utilizados para a prática delituosa.

Identificou-se que a assertividade do software aumenta com incremento do número de eventos seriados utilizados numa análise. Na pesquisa, houve uma média de nove eventos, o que atingiu raio de acerto esperado médio de $6,94 \%$, sendo esse um bom índice de acurácia para o software utilizado com os dados da pesquisa se comparado com outros trabalhos já publicados.

O estudo contribui no campo acadêmico para o preenchimento de uma lacuna referente à carência de constructos teóricos e análises empíricas no escopo da Geografia do Crime, notadamente na literatura técnica dedicada ao assunto em idioma português.

Além das conclusões elencadas, foi possível descortinar aspectos espaciais do fenômeno criminal seriado e seus autores, bem como identificar aspectos que tenham potencial para desenvolver informações e conhecimentos aplicados à prevenção e repressão criminal, como o geoprofile, o que distingue o aspecto prático e aplicado do trabalho científico desenvolvido.

A partir das conclusões do trabalho é possível sugerir o fomento à atividade de inteligência de segurança pública dedicada a conhecer com profundidade o perfil geográfico e o modus operandi dos criminosos em série, e com o intuito de se prevenir, detectar e neutralizar suas atividades desviantes além de incentivar ações de repressão qualificada direcionada ao encarceramento de autores prolíficos, o que tende a contribuir para a diminuição das taxas criminais.

É razoável o investimento na aquisição de software e a adoção de treinamento para análise de perfil geográfico criminal, e para que as atividades de prevenção criminal possam incluir as bases operacionais dos agentes, além dos locais de cometimento dos crimes, conforme se observa no desenvolvimento dos planejamentos operacionais de policiamento ostensivo, geridos pelas agências de segurança.

Não menos importante é a proposta de inserção do perfil geográfico na atividade de investigação criminal, para eventos cometidos por criminosos em série.

\section{AGRADECIMENTOS}

Os autores agradecem à Coordenação de Aperfeiçoamento de Pessoal de Nível Superior (CAPES) pela bolsa de doutorado que viabilizou a realização desta pesquisa. Agradecem também à Empresa ECRI Canadá por viabilizar a utilização do software RIGEL.

\section{REFERÊNCIAS}

ALLEMAN, AUSTIN C. Geographic Profiling through six-dimensional nonparametric density estimation. [s.d]. Disponível em: http://www.appliedmathematician.org/students/siuro/vol5/S01127. pdf. Acessado em: 01 Jul.2017.

BRANTINGHAM, Paul J.; BRANTINGHAM, Patricia L. (Ed.). Environmental criminology. Beverly Hills, CA: Sage Publications, 1981.

BRANTINGHAM, Paul J.; BRANTINGHAM, Patricia L. Patterns in crime. New York: Macmillan, 1984.

BRASIL. Código Penal Brasileiro. Decreto-Lei № 2.848, de 7 de dezembro de 1940. Brasília: Senado Federal, 1940. Disponível em: http://www.planalto.gov.br/ccivil_03/decreto- lei/Del2848compilado.htm. Acesso em: 08 Jul. 2017.

BURSIK, Robert J. Social disorganization and theories of crime and delinquency: Problems and prospects. Criminology, v. 26, n. 4, p. 519-552, 1988. https://doi.org/10.1111/j.1745-9125.1988.tb00854.x

CANTER, David; COFFEY, T.; HUNTLEY, M.; MISSEN, C. Predicting serial killers' home base using a decision support system. Journal of quantitative criminology, v. 16, n. 4, p. 457-478, Springer Nature Switzerland AG, 2000. https://doi.org/10.1023/A:1007551316253

CANTER, David. Psychology of offender profiling. Handbook of psychology in legal contexts, 1994.

$\begin{array}{lllll}\text { Caminhos de Geografia } & \text { Uberlândia-MG } & \text { v. 21, n. } 74 & \text { Abr/2020 } & \text { p. 51-67 Página } 66\end{array}$


CANTER, David. Offender profiling and investigative psychology. Journal of Investigative Psychology and Offender Profiling, v. 1, n. 1, p. 1-15, Wiley Online Library, 2004. https://doi.org/10.1002/jip.7

CANTER, D. Confusing operational predicaments and cognitive explorations: comments on Rossmo and Snook et al. Applied Cognitive Psychology: The Official Journal of the Society for Applied Research in Memory and Cognition, v. 19, n. 5, p.663-668, 2005. https://doi.org/10.1002/acp.1143

CANTER, David V..; GREGORY, Adam. Identifying the residential location of rapists. Journal of the Forensic Science Society, v. 34, n. 3, p. 169-175, 1994. https://doi.org/10.1016/S0015-7368(94)72910-8

CANTER, David V.; YOUNGS, Donna E. Principles of geographical offender profiling. Ashgate Publishing Ltd, 2008.

ECRI. Environmental Criminology Research Inc. Geographic Profiling with RIGEL.Vancouver: ECRI, 2012.

FELSON, Marcus. Linking Criminal Choices, Routine Activities, Informal Control, and. The Reasoning Criminal: Rational Choice Perspectives on Offending, p. 119, 1986. https://doi.org/10.1007/978-1-4613$\underline{8625-48}$

KAHN, Túlio. Além das Grades: radiografia e alternativas ao sistema prisional. Ebook. São Paulo: Editora Conjuntura, 2014.

KIND, Stuart S. Navigational ideas and the Yorkshire Ripper investigation. The Journal of Navigation, v. 40, n. 3, p. 385-393, Cambridge University Press, 1987. https://doi.org/10.1017/S0373463300000631

KIND, Stuart S. The Sceptical Witness: Concerning the Scientific Investigation of Crime Against a Human Background. Forensic Science Society, 1999.

PAULSEN, Derek J.; ROBINSON, Matthew B. Spatial aspects of crime: Theory and practice. Allyn \& Bacon, 2004.

ROSSMO, D. K. Fugitive migration patterns. Unpublished master's thesis, Simon Fraser University, 1987.

ROSSMO, D. Kim. Place, space, and police investigations: Hunting serial violent criminals. In: WISBURD, D.; ECK, J. E. Crime and place. 1995.

ROSSMO, D. Kim. Geographic profiling. Boca Raton, FL: CRC Press, 1999. https://doi.org/10.1201/9781420048780

ROSSMO, D. K. Evaluation of geographic profiling search strategies. Paper presented at the meeting of the American Society of Criminology, Atlanta, GA, 2001.

ROSSMO, D. Kim. An evaluation of NIJ's evaluation methodology for geographic profiling software. response to National Institute of Justice's A Methodology for Evaluating Geographic Profiling Software: Final Report, 2005.

Recebido em: 06/04/2019

Aceito para publicação em: 12/02/2020 